Cinémas

Revue d'études cinématographiques

Journal of Film Studies

\title{
Un mot du directeur de la revue
}

\section{André Gaudreault}

Volume 11, numéro 2-3, printemps 2001

Eisenstein dans le texte

URI : https://id.erudit.org/iderudit/024843ar

DOI : https://doi.org/10.7202/024843ar

Aller au sommaire du numéro

Éditeur(s)

Cinémas

ISSN

1181-6945 (imprimé)

1705-6500 (numérique)

Découvrir la revue

Citer ce document

Gaudreault, A. (2001). Un mot du directeur de la revue. Cinémas, 11(2-3), 7-8.

https://doi.org/10.7202/024843ar d'utilisation que vous pouvez consulter en ligne.

https://apropos.erudit.org/fr/usagers/politique-dutilisation/ 


\section{Un mot du directeur de la revue}

C'est sur ce numéro consacré à Eisenstein que la revue CiNéMAS boucle sa onzième année d'existence. Dirigée jusqu'en juin 1999 par mon collègue Michel Larouche, dont on se doit de saluer le courage de pionnier, la revue a su trouver sa place sur le "marché» des revues savantes en études cinématographiques. Elle a su s'imposer lentement mais sûrement, comme il est dit de ces phénomènes dont on sent bien que, même s'ils ne sont pas fulgurants, ils n'en sont pas moins inéluctables. C'est dans un esprit de continuité que j'ai, pour ma part, repris le flambeau de la direction, il y a maintenant près de deux ans. Une continuité qui n'a pas empêché, de la part de la nouvelle équipe, quelques tentatives de bonds en avant, pour assurer la consolidation de la revue, notamment sur le plan de sa diffusion et de sa dissémination.

Il me semblait en tout cas opportun, avec le présent numéro, de marquer le pas et de remercier de façon particulière ceux qui, par la solidarité de leur engagement financier envers la revue, font que nous existons : nos abonnés. Et, partant, ces abonnés en puissance que sont tous nos lecteurs. C'est maintenant chose faite, avec ce numéro spécial sur Eisenstein, plus imposant encore que le numéro double "régulier", par sa taille certes, mais aussi, souhaitons-le, par la qualité de son aspect "documentaire», qui en fera un nouvel outil de référence pour les chercheurs, en matière d'études eisensteiniennes. Un numéro qui fut difficile à monter, on peut l'imaginer, et qui a demandé des soins de tous les instants de la part de l'équipe de rédaction et de la part du responsable du numéro, François Albera, qui a fait preuve d'une patience et d'une détermination à toute épreuve lors du processus de préparation de l'ensemble'.

Que ce numéro contribue à la poursuite de l'implantation de la revue CiNéMAS, c'est ce que nous, de l'équipe de direction et de rédaction, souhaitons. Si, en plus, nos efforts contribuent à la relance des études eisensteiniennes, dont le mouvement est, ces 
temps derniers, sensible dans la communauté des chercheurs, nous aurons atteint doublement notre cible : celle du développement des études cinématographiques.

André Gaudreault directeur

1. Je lève aussi mon chapeau à Denyse Therrien, qui a assuré la toute première révision des textes et la préparation du manuscrit, de même que Marco Santos et Dominique Robert, qui ont abattu l'énorme travail de correction des épreuves et d'homogénéisation des textes et notations. 